\title{
'Mini munchers' to control powdery mildew and botrytis bunch rot in grapes
}

\author{
K.S.H. Boyd-Wilson ${ }^{1}$, S. Read ${ }^{1}$ and D.C. Mundy ${ }^{2}$ \\ ${ }^{1}$ The New Zealand Institute for Plant E Food Research Limited (Plant E Food Research), Private Bag \\ 4704, Christchurch, New Zealand \\ ${ }^{2}$ Plant E Food Research, P.O. Box 845, Blenheim, New Zealand \\ Corresponding author:Kirsty.boyd-wilson@plantandfood.co.nz
}

The use of mycophagous (fungal feeding) invertebrates has potential to contribute to disease management in both organic and conventional wine production systems in New Zealand. The New Zealand wine industry is actively working towards producing ultra-low residue wines. This involves removing all late season botrytis fungicide sprays from the vineyard spray programme. In organic wine production systems in New Zealand, the only products available to control powdery mildew and botrytis bunch rot are protectants. In both these systems when fungicides are not available, mycophagous invertebrates may reduce the amount of inoculum available to cause disease. A survey of leaf material in 19 vineyards in Canterbury and Marlborough over the 2008-2009 growing season identified populations of beetles in two vineyards in sufficient numbers to justify further research. In the laboratory, field-collected beetles that were starved for 2 days, fed on spores of Botrytis cinerea (botrytis bunch rot) growing on blackcurrant flowers, Podosphaerea leucotricha (apple powdery mildew) on apple leaves and Erysiphe necator (grape powdery mildew) on grape leaves. Beetles were identified as Aridius bifaciatus (Reitter), A. nodifer (Westwood) and Cortinicara hirtalis (Broun).

\section{Calcium chloride against black spot on apples}

\author{
K.S.H. Boyd-Wilson, R.C. Butler and M. Walter \\ The New Zealand Institute for Plant E Food Research Limited (Plant E Food Research), Private Bag \\ 4704, Christchurch, New Zealand \\ Corresponding author:Kirsty.boyd-wilson@plantandfood.co.nz
}

Calcium chloride, which is classified as "generally recognised as safe" (GRAS) under the Agricultural Compounds and Veterinary Medicines Regulations 2001, has potential for use in an organic apple production system against black spot (Venturia inaequalis). The effectiveness of calcium chloride on control of black spot was evaluated in a field trial over the 2007/2008 growing season. Calcium chloride was applied 10 times over the season at the commercially-recommended rate of $0.33 \mathrm{~kg}$ product $/ 100$ litres or at $2 \mathrm{~kg} / 100$ litres (the latter treatment was halved after two applications due to foliar damage). At harvest, fruit treated with the high rate of calcium chloride had a lower disease incidence of $41 \%$ than the water control, which had $97 \%$ incidence $(\mathrm{P}<0.001)$. The number of lesions on fruit treated with the high rate of calcium chloride was $10 \%$ of that of the water-treated fruit $(\mathrm{P}<0.05)$. The incidence of black spot on leaves was assessed three times during the season. The incidence was lower $(\mathrm{P}<0.001)$ for the high rate calcium chloride treatment at all three assessments. 